\title{
Mapping translocation breakpoints by next-generation sequencing
}

Wei Chen, ${ }^{1,9}$ Vera Kalscheuer, ${ }^{1}$ Andreas Tzschach, ${ }^{1}$ Corinna Menzel, ${ }^{1}$ Reinhard Ullmann, ${ }^{1}$ Marcel Holger Schulz, ${ }^{1,2}$ Fikret Erdogan, ${ }^{1} \mathrm{Na} \mathrm{Li},{ }^{1}$ Zofia Kijas, ${ }^{1}$ Ger Arkesteijn, ${ }^{3}$ Isidora Lopez Pajares, ${ }^{4}$ Margret Goetz-Sothmann, ${ }^{5}$ Uwe Heinrich, ${ }^{6}$ Imma Rost, ${ }^{6}$ Andreas Dufke, ${ }^{7}$ Ute Grasshoff, ${ }^{7}$ Birgitta Glaeser, ${ }^{8}$ Martin Vingron, ${ }^{1}$ and H. Hilger Ropers ${ }^{1}$

\author{
${ }^{1}$ Max Planck Institute for Molecular Genetics, 14195 Berlin, Germany; ${ }^{2}$ International Max-Planck Research School for \\ Computational Biology and Scientific Computing, 14195 Berlin, Germany; ${ }^{3}$ Department of Infectious Diseases and Immunology, \\ Faculty of Veterinary Medicine, Utrecht University, 3508 TC Utrecht, The Netherlands; ${ }^{4}$ Department of Genetics, Hospital \\ Universitario La Paz, 28046 Madrid, Spain; ${ }^{5}$ Practice of Human Genetics, 81379 Munich, Germany; ${ }^{6}$ Centre of Human Genetics, \\ 82152 Martinsried, Germany; ${ }^{7}$ Department of Medical Genetics, Eberhard Karls University, 72076 Tuebingen, Germany; \\ ${ }^{8}$ Institut für Klinische Genetik, Olgahospital, 70176 Stuttgart, Germany
}

\begin{abstract}
Balanced chromosome rearrangements (BCRs) can cause genetic diseases by disrupting or inactivating specific genes, and the characterization of breakpoints in disease-associated BCRs has been instrumental in the molecular elucidation of a wide variety of genetic disorders. However, mapping chromosome breakpoints using traditional methods, such as in situ hybridization with fluorescent dye-labeled bacterial artificial chromosome clones (BAC-FISH), is rather laborious and time-consuming. In addition, the resolution of BAC-FISH is often insufficient to unequivocally identify the disrupted gene. To overcome these limitations, we have performed shotgun sequencing of flow-sorted derivative chromosomes using "next-generation" (Illumina/Solexa) multiplex sequencing-by-synthesis technology. As shown here for three different disease-associated BCRs, the coverage attained by this platform is sufficient to bridge the breakpoints by PCR amplification, and this procedure allows the determination of their exact nucleotide positions within a few weeks. Its implementation will greatly facilitate large-scale breakpoint mapping and gene finding in patients with disease-associated balanced translocations.
\end{abstract}

[Supplemental material is available online at www.genome.org. Solexa sequencing data have been submitted to the Short Read Archive at NCBI (http://www.ncbi.nlm.nih.gov/Traces/sra/sra.cgi?) and are accessible through accession no. SRA000261. ArrayCGH data have been submitted to the Gene Expression Omnibus (http://www.ncbi.nlm. nih.gov/geo/) and are accessible through GEO Series accession no. GSE1O115.]

De novo balanced translocations have a prevalence of about one in every 2000 live births, and $\sim 6 \%$ of these cases are associated with congenital malformations and/or developmental delay (Warburton 1991). This proportion is about twice as high as in the general population, suggesting a causative link between the rearrangements and the observed phenotype in at least half of the disease-associated balanced translocations (DBCRs). In most of the patients with DBCRs, aberrant phenotypes are due to truncation of genes, and 50\% of these patients with DBCRs are mentally retarded (Bugge et al. 2000). Therefore, DBCRs are a unique resource for bridging genotypes and phenotypes in patients with mental retardation and other early-onset Mendelian disorders, but DBCRs have also been characterized to search for genetic risk factors for complex and late-onset diseases, as discussed below.

Mapping chromosome breakpoints using traditional methods, such as FISH, is rather laborious and time-consuming; moreover, the resolution of this method is often limited, particularly if fluorescence-labeled bacterial artificial chromosome (BAC)

${ }^{9}$ Corresponding author.

E-mail wei@molgen.mpg.de; fax 49-30-84131383.

Article published online before print. Article and publication date are at http:// www.genome.org/cgi/doi/10.1101/gr.076166.108. probes are employed. With the development of the array painting technique, the efficiency has been greatly improved. Upon array painting, the two derivative chromosomes are isolated by flow sorting, differentially labeled, and hybridized onto DNA arrays. Since the chromosome segments located on either side of the breakpoint are labeled with different fluorescent dyes, plotting the fluorescence ratio of probes ordered along the chromosome can reveal the breakpoint flanking region, while breakpoint spanning probes usually show intermediate ratios (Fiegler et al. 2003; Veltman et al. 2003; Backx et al. 2007). Only recently, the resolution of this method has been increased by sequential painting with two arrays, a tiling path large insert array, and a regionspecific, ultra-high-resolution oligonucleotide array (Gribble et al. 2007).

At least theoretically, shotgun sequencing of sorted derivative chromosomes is another way to map chromosomal breakpoints, but this approach is prohibitively costly if based on conventional Sanger sequencing. However, the recent introduction of novel multiplex sequencing-by-synthesis technology has reduced the costs of sequencing by several orders of magnitude. With the Illumina/Solexa system, which is based on massively parallel sequencing of millions of fragments using the propri- 


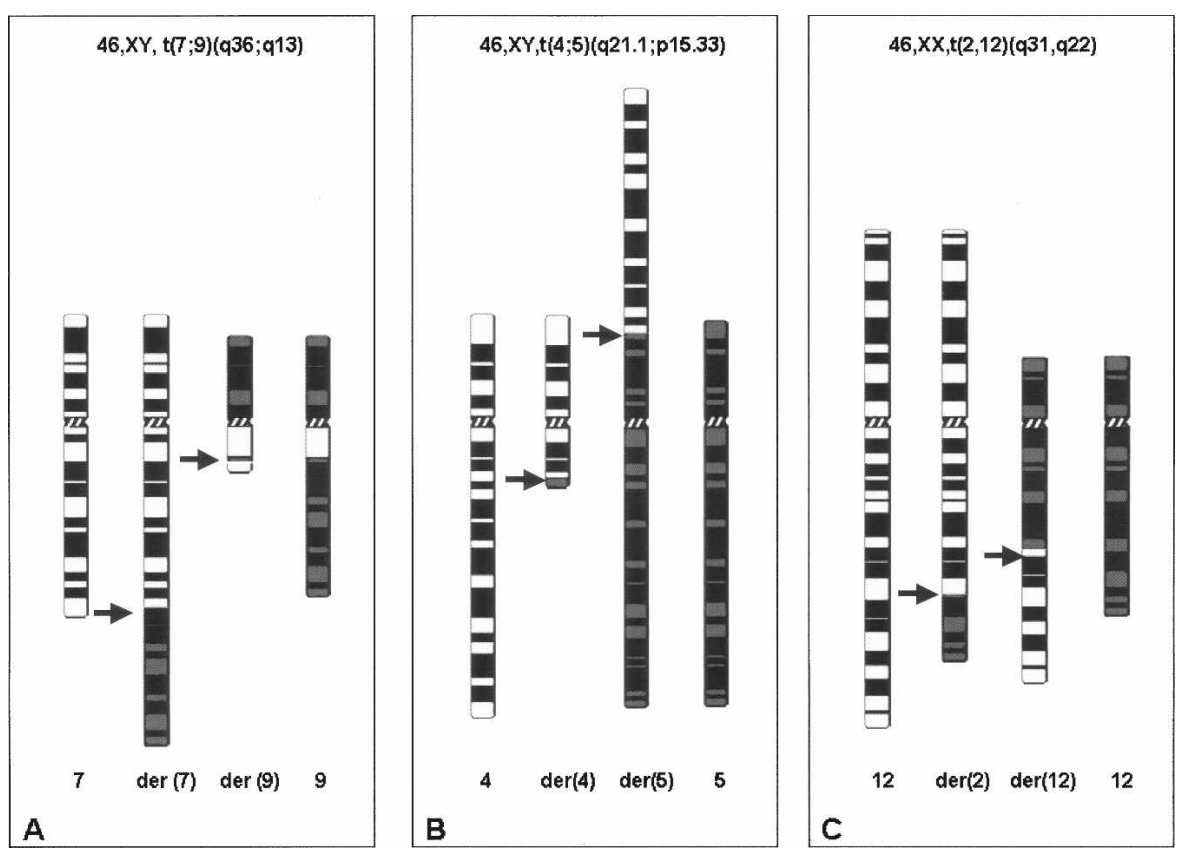

Figure 1. Ideograms of the derivative chromosomes from the patients. $(A)$ Patient $1,(B)$ patient 2 , (C) patient 3. (Arrows) Breakpoints.

etary Clonal Single Molecule Array technology and novel reversible terminator-based sequencing chemistry (for further details, see http://www.illumina.com/pages.ilmn?ID=203), more than 30 million short sequence reads can be produced in a single experiment. In theory, the density of this coverage should suffice to define primers for the amplification and subsequent Sanger sequencing of breakpoint-spanning PCR fragments.

Here, we have made use of this principle to map and sequence the breakpoint regions on flow-sorted derivative chromosomes from three unrelated mentally retarded patients with de novo balanced chromosomal translocations. In all of these patients, we identified suggestive novel candidate genes for mental retardation (MR) that were truncated by the chromosomal rearrangements. This study demonstrates the potential of this approach for large-scale breakpoint mapping and gene finding in patients with disease-associated balanced translocations.

\section{Results}

One derivative chromosome from each patient was flow-sorted and sequenced using the Illumina $1 G$ analyzer, and sequence reads were aligned to reference sequences of the two corresponding chromosomes. Due to incomplete separation of derivative chromosomes from their normal counterparts upon flow sorting, we had to assess the transition point between high and low sequencing coverage by maximum likelihood estimation (see Supplemental Methods). This procedure, and the high number of sequencing reads generated by the $1 \mathrm{G}$ analyzer, enabled us to map all breakpoints precisely enough to allow direct amplification and sequencing of the junction fragments.

In patient 1 (46XY, t(7;9)(q36;q13); see Fig. 1A), the der (9) chromosome was sequenced in one lane of a flow cell. In total, 199,421 and $1,047,649$ reads mapped uniquely to chromosomes 7 and 9 , respectively (Table 1 ). The average coverage of der (9) was $\sim 18$ reads per kilobase. Based on the distribution of sequence reads (Fig. 2), maximum likelihood estimation assigned the chromosome 7 breakpoint to position $156,288,272$ and the breakpoint on chromosome 9 to position 71,021,542. To amplify the junction fragment of the der (9) chromosome, primers flanking the breakpoint were then designed and used for PCR amplification from the patient's genomic DNA. This yielded a PCR product of $\sim 2.4 \mathrm{~kb}$, which was subsequently sequenced. Precise breakpoint junctions were determined through alignment with the reference sequences of chromosomes 7 and 9, and results were confirmed by PCR with primer pairs flanking the breakpoint on the der (7) chromosome. In this way, the respective breakpoints could be mapped between nucleotides $156,288,232$ and 156,288,233 on chromosome 7, and between nucleotides 71,021,561 and 71,021,562 on chromosome 9 (NCBI build 35, Fig. 3A).

The same procedure was applied to patient 2 $(46, \mathrm{XY}, \mathrm{t}(4 ; 5)(\mathrm{q} 21.1 ; \mathrm{p} 15.33)$, Fig. $1 \mathrm{~B})$ and patient 3 $(46, X X, t(2 ; 12)(\mathrm{q} 31 ; \mathrm{q} 22)$, Fig. 1C). In patient 2 , the der (5) chromosome was sequenced. In total, 509,023 and 641,701 reads were obtained for chromosomes 4 and 5 , respectively. The average coverage of der (5) was 3.7 reads per kilobase, which enabled us to localize the corresponding breakpoints at or near position $66,330,277$ on chromosome 4 and close to position 2,978,264 on chromosome 5 . By sequencing junction fragments, we could map the breakpoint on chromosome 4 to a deleted interval of 18 bp between nucleotides 66,329,510 and 66,329,529, and the breakpoint on chromosome 5 between base pairs 2,977,374 and 2,977,375 (NCBI build 35, Fig. 3B). In patient 3, we sequenced der (12). 201,627 and 165,160 reads mapped to unique sequences of chromosomes 2 and 12, respectively, with a mean coverage of

Table 1. Breakpoint position estimated from Solexa sequencing and direct Sanger sequencing

\begin{tabular}{|c|c|c|c|c|}
\hline Patient & Chromosome & $\begin{array}{l}\text { No. of mapped Solexa } \\
\text { sequencing reads }\end{array}$ & $\begin{array}{l}\text { Breakpoint position from } \\
\text { Solexa sequencing }\end{array}$ & $\begin{array}{l}\text { Breakpoint position from } \\
\text { Sanger sequencing }\end{array}$ \\
\hline \multirow[t]{2}{*}{1} & 7 & 199,421 & $156,288,272$ & $156,288,232-156,288,233$ \\
\hline & 9 & $1,047,649$ & $71,021,542$ & $71,021,561-71,021,562$ \\
\hline \multirow[t]{2}{*}{2} & 4 & 509,023 & $66,330,277$ & $66,329,510-66,329,529$ \\
\hline & 5 & 641,701 & $2,978,264$ & $2,977,374-2,977,375$ \\
\hline \multirow[t]{2}{*}{3} & 2 & 201,627 & $156,796,485$ & $156,795,885-156,796,293$ \\
\hline & 12 & 165,160 & $84,970,972$ & $84,970,997-84,970,999$ \\
\hline
\end{tabular}

\section{Genome Research}

www.genome.org 


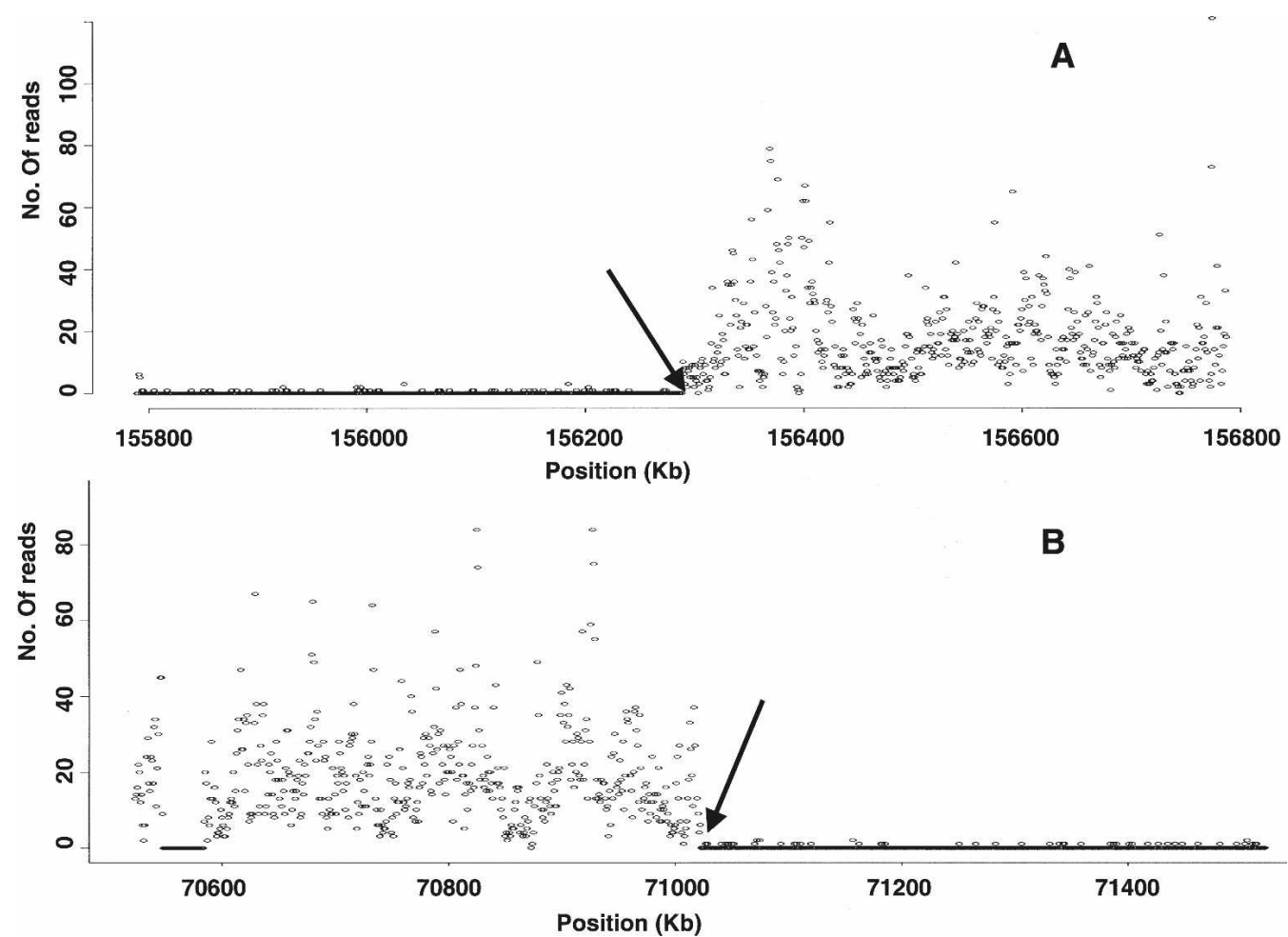

Figure 2. Solexa sequencing profile of derivative chromosome 9 from patient 1 . 1-Mb intervals around the breakpoints on chromosome $7(A)$ and $9(B)$ are shown. 199,421 and 1,047,649 reads derived from the der (9) were mapped to unique positions on normal chromosomes 7 and 9 , respectively. The number of reads was then binned into nonoverlapping 1-kb segments and plotted against the chromosome coordinates. (Arrows) Breakpoints.

1.7 reads per kilobase for the der (12). Primers were designed on both sides of the estimated breakpoint position to amplify the junction fragments (Fig. 4). Subsequent Sanger sequencing mapped the breakpoint on chromosome 2 between nucleotides $84,970,997$ and $84,970,999$ with a 1 -bp deletion, and the other breakpoint to a deleted interval of $407 \mathrm{bp}$ between nucleotides

A

Chr7 (+) CCCCTGCCCCTCCCCCTCCCCTCCATTCCCCTCCCTTCCTTCTTTTTTCTTTTGTTAGAT Der7 CCCCTGCCCCTCCCCCTCCCCTCCATTCCCCAGGAGCATGAACCCTGCTGTGAACTGTGC Der9 TGTCACATTAGCATTGGCATTAAATTCTCACTCCCTTCCTTCTTTTTTTCTT'TTGTTAGAT Chr9 (+) TGTCACATTAGCATTGGCATTAAATTCTCACAGGAGCATGAACCCTGCTGTGAACTGTGC

B $\begin{array}{ll}\text { Chr4 (+) } & \text { ACTATTGTCAAAATCTGAGTACCAGAATGGAAAATCCAGCTTAAGTTCT TCTTGATTCAG } \\ \text { Der4 } & \text { ACTATTGTCAAAATCTGAGTACCAGAATGCAACTCAGGAGGTGGAGGTGCAGTGAGCCG } \\ \text { Der5 } & \text { TACTGGGAGGCTGAGGCAGGAGAATCAC CTTCTTGATTCAG } \\ \text { Chr5 (-) } & \text { TACTGGGGAGGCTGAGGCAGGAGAATCACCAACTCAGGAGGTGAGGTGCAGTGAGCCG }\end{array}$

C

Chr2 (+) CAATGAAGTTAGAATCTCAAATAATGGAG. C. CTGGTCACTTTGTAACAAGCAAAAGCA

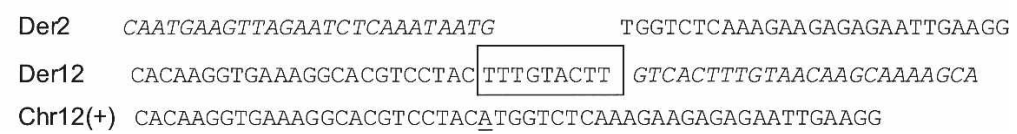

Figure 3. Junction fragment sequences in patients $1(A), 2(B)$, and $3(C)$. Normal reference sequences are labeled in italic and normal characters, respectively. Deleted sequences are underlined. (Black box) The 9-bp insertion on the der (12) of patient 3. (Chr) Chromosome, (Der) derivative chromosome.
$156,795,885$ and $156,796,293$ on chromosome 12 (NCBI build 35 , Fig. 3C). Interestingly, 9 bp of the breakpoint sequence on the nor to chromosome 2

To identify interspersed repetitive elements in the vicinity of the breakpoints, we referred to the UCSC Genome Browser (NCBI build 35 ). In patient 1 , the breakpoints on chromosomes 7 and 9 were spanned by DNA repeats of the MER1 and MER2 type, respectively. In patient 2 , no repeats were found $1 \mathrm{~kb}$ upstream or downstream of the breakpoint on chromosome 4, whereas the breakpoint on chromosome 5 was within a short interspersed element (SINE) belonging to the Alu family. In patient 3, a DNA repeat of the MER1 type was detected within the breakpoint interval on chromosome 2, and a MaLR family repeat was found to span the breakpoint on chromosome 12 .

\section{Discussion}

Balanced chromosome rearrangements can cause genetic diseases by disrupting or inactivating specific genes, forming a visible bridge between human phenotypes and genotypes. Characterization 


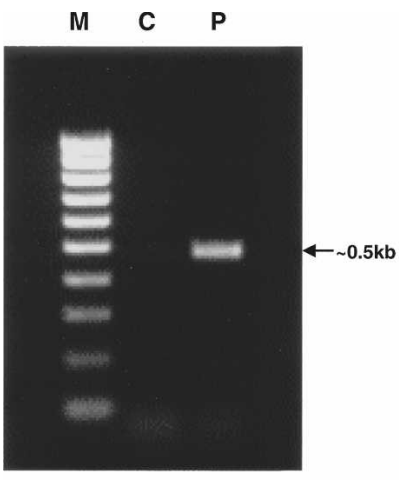

$\operatorname{der}(2)$

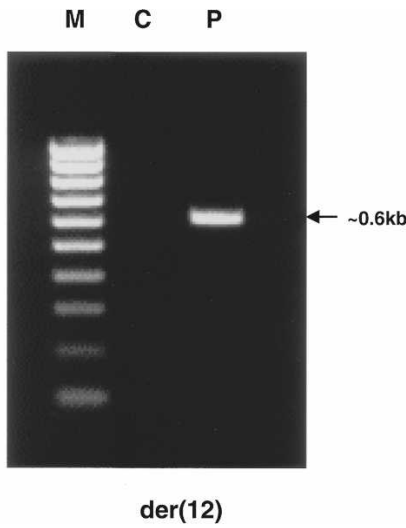

Figure 4. $\quad P C R$ products of the two junction fragments from patient 3. $(\mathrm{M})$ Size marker, (C) genomic DNA from a normal individual, $(P)$ genomic DNA from patient 3, (der) derivative chromosome.

of breakpoints in disease-associated balanced translocations (DBCRs) has led to the molecular elucidation of many hereditary diseases (Tommerup 1993; Wirth et al. 1999; Bugge et al. 2000). More than a decade ago, the Mendelian Cytogenetics Network (MCN) was established to study DBCRs in a systematic fashion (Tommerup 1993; Bugge et al. 2000), and, more recently, similar programs to characterize DBCRs have been initiated elsewhere (Alkuraya et al. 2006; Lu et al. 2007; Williamson et al. 2007).

To speed up the characterization of breakpoints in patients with DBCRs and to overcome the resolution limits of conventional FISH mapping with BAC probes, we have now employed next-generation sequencing as a fast and highly accurate way to localize the breakpoints in DNA from sorted derivative chromosomes. Solexa sequencing enabled us to map the chromosomal breakpoints with an error margin of $<1000 \mathrm{bp}$, precisely enough to define a single primer pair for PCR amplification of the junction fragment, and to determine the exact sequence around the breakpoint in one single step. To infer the position of breakpoints, only sequencing reads mapping to unique sites in the genome were employed. Mapping of breakpoints may be very difficult with this procedure if they are located in large duplicated segments of the genome, but this is also true for other approaches such as array painting.

As shown here, sequencing the breakpoint regions in three mentally retarded patients with reciprocal translocations has enabled us to identify three promising, truncated candidate genes, which had not been implicated in MR previously. In patient 1, the breakpoint on chromosome 7q36 maps to an intergenic region that is flanked by the 3 ' ends of two genes, NOM1 and MNX1; neither of these is a plausible functional candidate gene for MR. In contrast, the breakpoint on chromosome 9 disrupts the 5 ' end of a splicing isoform (accession no. AL136545) of the TRPM3 gene (Fig. 5A). The product of this gene belongs to the family of transient receptor potential (TRP) channels, which are important for cellular calcium signaling and homeostasis. Given the expression of this isoform in the brain, it is quite possible that its disruption by the chromosome rearrangement contributes to the MR phenotype of patient 1.

In patient 2, the breakpoint on chromosome 4 disrupts EPHA5, a member of the Ephrin receptor family (Fig. 5B); there are no known genes in the vicinity of the other breakpoint on

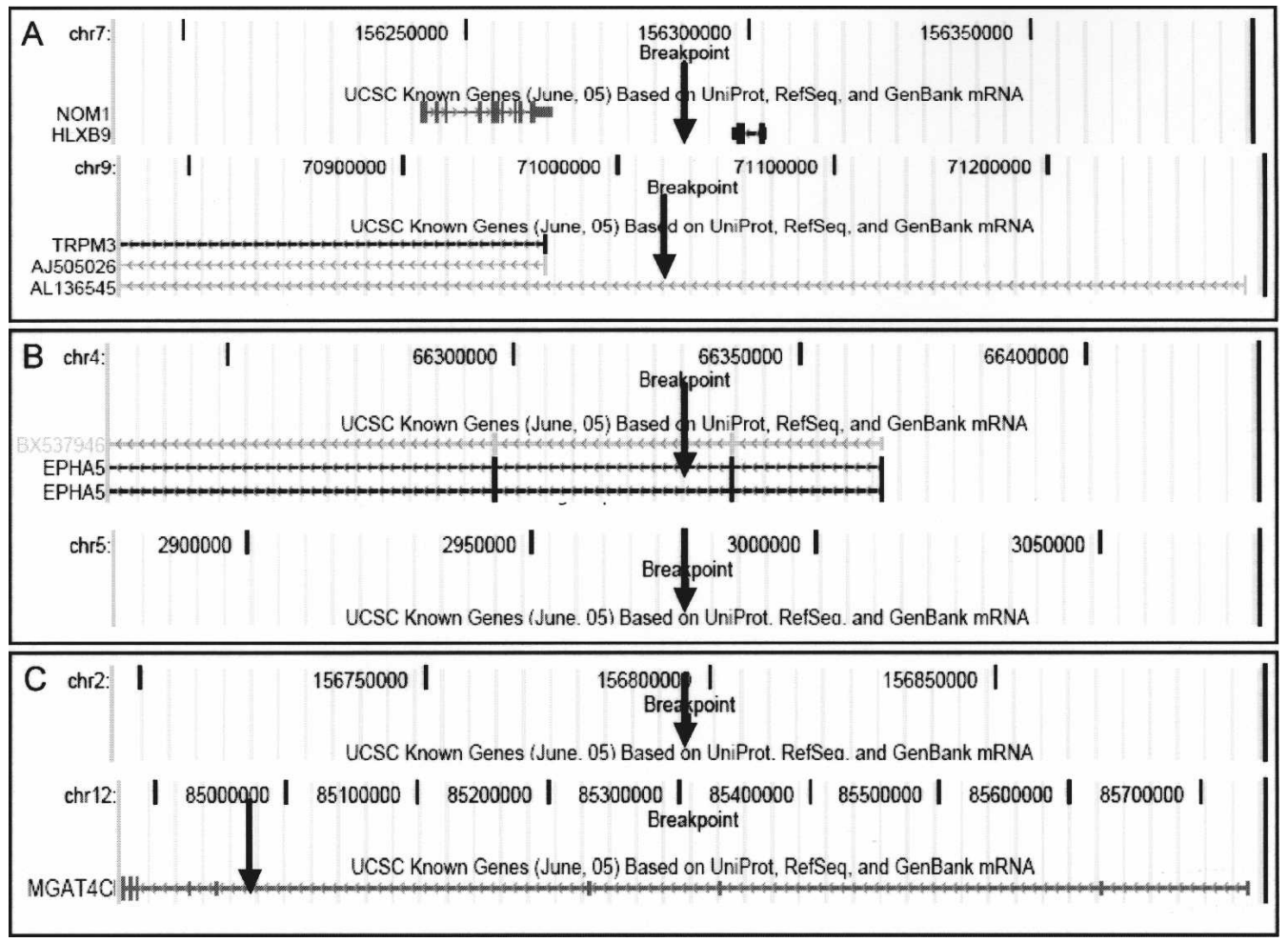

Figure 5. Chromosome breakpoints (arrows) and disrupted genes. (A) Patient 1: Breakpoint on chromosome 7 maps between the 3 ' ends of NOM1 and MNX1 (formerly known as HLXB9); breakpoint on chromosome 9 disrupts the $5^{\prime}$ end of a splicing isoform (accession no. AL136545) of TRPM3. (B) Patient 2: Breakpoint on chromosome 4 disrupts EPHA5; no known genes are in the vicinity of the breakpoint on chromosome 5. (C) Patient 3: Breakpoint on chromosome 12 disrupts MAGT4C; no known genes are close to the breakpoint on chromosome 2.

\section{Genome Research}

www.genome.org 
chromosome 5. EPH and EPH-related receptors have an important role in the establishment of topographic maps, especially in the nervous system (Drescher et al. 1997). In EPHA5 knockout mice, the retino-tectal map was abnormal, with temporal and nasal axons terminating in incorrect regions (Feldheim et al. 2004). It is therefore plausible that the clinical symptoms in patient 2 are related to the disruption of EPHA5.

Similarly, only one of the breakpoints of patient 3 , that on chromosome 12, disrupts a known gene, and, as in patient 1 and patient 2, it is an interesting candidate that has not yet been directly implicated in MR. The relevant gene, MGAT4C (Fig. 5C), encodes mannosyl (alpha-1,3-)-glycoprotein beta-1,4-Nacetylglucosaminyltransferase, isozyme $\mathrm{C}$, which is one of the key glycosyltransferases regulating the formation of tri- and other multiantennary Asn-linked sugar chains and expresses in fetal and adult brain (Gleeson and Schachter 1983; Schachter et al. 1989). Genetic defects of protein glycosyltransferases have emerged as an important cause of (mostly syndromic) forms of MR. Very recently, mutations involving a putative member of this family, TUSC3, have been observed in two unrelated families with nonsyndromic MR (Molinari et al. 2007; Garshasbi et al. 2008). Thus, it is quite conceivable that the MR in patient 3 is due to the truncation of the MAGT4C gene.

Due to the limited number of balanced translocations that have been analyzed in detail, relatively little is still known about the involvement of specific sequences in the generation of such rearrangements. In the three reciprocal translocations described here, interspersed repeats were detected at five out of six breakpoints. Repetitive elements have been implicated as the sites of chromosome instability, and the apparent enrichment of repetitive sequences around the breakpoints in this study may indicate that these elements have a role in the generation of balanced translocations. However, no significantly homologous sequences were found to flank the two breakpoints in each of the three patients. This argues against nonallelic homologous recombination (NAHR) as the mechanism underlying these rearrangements. Thus, it is more likely that they were generated through nonhomologous end joining, which is in keeping with previous observations (Erdogan et al. 2006).

Hitherto, breakpoint analysis in patients with balanced chromosome rearrangements has focused on congenital or earlyonset disorders. However, balanced chromosome rearrangements were also shown to be associated with complex and late-onset disorders, as documented by the identification of candidate genes for diabetes, schizophrenia, dyslexia, Tourette syndrome, and psoriasis (Blackwood et al. 2001; Gloyn et al. 2002; Taipale et al. 2003; Abelson et al. 2005; Tzschach et al. 2006), and systematic re-examination of previously healthy carriers of balanced reciprocal translocations has identified several rearrangements that seem to predispose to late-onset, complex diseases (Bache et al. 2006). However, given the frequency of complex disorders, it will be a major challenge to distinguish these "causative" associations from the many others where apparent associations between balanced rearrangements and common disorders are due to chance. Therefore, our method, which greatly facilitates breakpoint mapping and sequencing, should also be an asset for the identification of genetic factors in the etiology of common disorders.

In this study, we have used flow sorting to separate the derivative chromosomes from each other and from their normal counterparts, but depending on the size of the relevant chromosomes, this approach is not always possible, and it cannot be employed to study inversions. As an alternative, microdissection has been used to isolate rearranged chromosomes, or a specific chromosome region in the case of inversions, and in principle it is feasible to use this approach in combination with nextgeneration sequencing if chromosome sorting is not an option. Finally, as the costs for high-throughput sequencing will continue to decrease, whole-genome paired-end sequencing may soon become a viable alternative to the procedure described here, allowing the characterization of DBCRs and the identification of the truncated genes in a single experiment, obviating prior isolation of rearranged chromosomes and chromosome segments. Technically, this is already feasible now (Korbel et al. 2007).

\section{Methods}

\section{Patients}

\section{Patient 1}

This male patient is the second child of healthy and nonconsanguineous parents. He suffered from delayed psychomotor development and congenital bilateral cataracts that had been operated at the age of 6 and $16 \mathrm{mo}$. On examination at the age of $17 \mathrm{yr}$, he had severe visual defects and mild mental retardation. Body measurements were within the normal range. Cytogenetic investigation revealed a $46 \mathrm{XY}, \mathrm{t}(7 ; 9)(\mathrm{q} 36 ; \mathrm{q} 13)$ karyotype in the patient. Both parents had normal karyotypes.

\section{Patient 2}

This boy is the first child of healthy and non-consanguineous parents. Psychomotor development was retarded (walking at age $2 \mathrm{yr}$ ). On examination at the age of $8 \mathrm{yr}$, he was severely mentally retarded. He was not able to talk and walked with an insecure gait. Brain MR scan showed no abnormalities. He had a horizontal nystagmus, but his vision was apparently normal, and ophthalmological investigations revealed no structural abnormalities. Cytogenetic investigation revealed a 46,XY,t(4;5)(q21.1;p15.33) karyotype in the patient. Karyotypes were normal in his two parents.

\section{Patient 3}

This female patient is the first child of healthy and nonconsanguineous parents. Her psychomotor development was delayed; at the age of 17 mo she could neither walk nor talk. An MRI scan revealed frontotemporal atrophy and delayed myelinization. Body measurements were within the normal range. She also suffered from sleep apnea. Cytogenetic investigations revealed a $46, \mathrm{XX}, \mathrm{t}(2 ; 12)(\mathrm{q} 31 ; \mathrm{q} 22)$ karyotype in the patient and normal karyotypes in her parents.

\section{Exclusion of clinically relevant DNA copy number variation}

To study submicroscopic deletions or duplications, comparative genome hybridization (CGH) experiments were performed in all three patients, using whole-genome tiling path BAC arrays, as previously described (Erdogan et al. 2006), and results were compared with previously described copy number variants (CNVs) and CNVs observed in $\sim 700$ unrelated probands screened for genomic imbalances in our laboratory using tiling path BAC arrays (Ullmann et al. 2007; Kirov et al. 2008). Except for a deletion of $\sim 360 \mathrm{~kb}$ on chromosome 5 (position 101,033,643-101,393,788 NCBI build 35 ) in patient 1 , no genomic imbalances larger than three consecutive clones were found that had not been observed also in healthy individuals. The $360-\mathrm{kb}$ deletion on chromosome 5q encompasses two known CNVs (locus 1513 and 1514, Data- 
base of Genome Variants, http://projects.tcag.ca/variation/), does not span known genes, and may be functionally neutral. Familial inheritance could not be studied due to lack of parental DNA. Array CGH data discussed in this publication have been deposited in NCBIs Gene Expression Omnibus (Barrett et al. 2007) and are accessible through GEO Series accession no. GSE10115.

\section{Chromosome sorting and amplification}

For chromosome sorting, the lymphoblastoid cell lines were cultured in RPMI 1640 medium supplemented with $10 \%$ fetal calf serum, $2 \mathrm{mM} \mathrm{L}$-glutamine, and antibiotics at $37^{\circ} \mathrm{C}$ in a humidified atmosphere containing 5\% $\mathrm{CO}_{2}$. Cells in log phase were treated for $16 \mathrm{~h}$ with colcemid $(0.05 \mathrm{mg} / \mathrm{mL}$ final concentration) to arrest cells in metaphase. Metaphase chromosomes were flow sorted as described previously (Arkesteijn et al. 1999). The sorted chromosomes were amplified using the GenomiPhi V2 DNA Amplification Kit following the protocol of the manufacturer.

\section{Chromosome sequencing using Solexa}

Approximately $2 \mu \mathrm{g}$ of amplified chromosomes was randomly fragmented to $<800$ bp by nebulization. Both ends of the DNA fragments were then repaired by $\mathrm{T} 4$ polymerase and Klenow DNA polymerase, and T4 polynucleotide kinase. Using Klenow exo ( $3^{\prime}$ to $5^{\prime}$ exo minus), a protruding " $\mathrm{A}$ " base was added to the 3 ' end of the DNA fragments for ligation with Solexa adaptors (with a " $\mathrm{T}$ " overhang). Following ligation, DNA fragments (size range 150-200 bp) were gel purified on 2\% agarose, followed by 18 cycles of PCR amplification. We measured the DNA concentration with a Nanodrop 7500 spectrophotometer, and a $1-\mu \mathrm{L}$ aliquot was diluted to $10 \mathrm{nM}$. Adaptor-ligated DNA was hybridized to the surface of flow cells, and DNA clusters were generated using the Illumina/Solexa cluster station, followed by 27 to 36 cycles of sequencing on the Illumina $1 \mathrm{G}$ analyzer, in accordance with the manufacturer's protocols.

\section{Data processing}

Sequence reads were compiled using a manufacturer-provided computational pipeline consisting of the open-source Firecrest and Bustard applications. Sequence reads from a derivative chromosome were then aligned with the sequence of its two normal counterparts (NCBI build 35) using the Eland application. Only uniquely mapped reads with fewer than two mismatches were retained. We then calculated the number of reads overlapping each nucleotide position along a specific chromosome. The change point problem is a natural framework to approach the breakpoint estimation problem. We used the Poisson process to model the random generation of sequencing reads along a chromosome. The breakpoint position was computed using the method of maximum likelihood estimation. Computer simulations confirmed the robustness of these estimates (for a more detailed description, see Supplemental Methods).

\section{PCR amplification and sequencing of junction fragments}

Junction fragments were amplified by long-range PCR using the Takara LA PCR kit version 2.1. Primers are listed in Supplemental Table 1, and PCR conditions are available upon request. PCR products were used as templates for sequencing in both directions using BigDye Terminator chemistry (PE Biosystems) on an Applied Biosystem 3730xl DNA Analyzer. Sequences of junction fragments were aligned to the human genome reference sequence (NCBI build 35) using BLAT from the UCSC Genome Browser (http://genome.ucsc.edu/cgi-bin/hgGateway).

\section{Acknowledgments}

The derivative chromosomes of patient 1 were sorted by J. Wienberg, Chrombios $\mathrm{GmbH}$, Raubling, Germany. The project was supported by the German National Genome Research Network (project nos. 01GR0105 and 01GR0414) and by a grant from the Max-Planck Innovation Funds (H.H.R.).

\section{References}

Abelson, J.F., Kwan, K.Y., O’Roak, B.J., Baek, D.Y., Stillman, A.A. Morgan, T.M., Mathews, C.A., Pauls, D.L., Rasin, M.R., Gunel, M., et al. 2005. Sequence variants in SLITRK1 are associated with Tourette's syndrome. Science 310: 317-320.

Alkuraya, F.S., Saadi, I., Lund, J.J., Turbe-Doan, A., Morton, C.C., and Maas, R.L. 2006. SUMO1 haploinsufficiency leads to cleft lip and palate. Science 313: 1751.

Arkesteijn, G., Jumelet, E., Hagenbeek, A., Smit, E., Slater, R., and Martens, A. 1999. Reverse chromosome painting for the identification of marker chromosomes and complex translocations in leukemia. Cytometry 35: 117-124.

Bache, I., Hjorth, M., Bugge, M., Holstebroe, S., Hilden, J., Schmidt, L. Brondum-Nielsen, K., Bruun-Petersen, G., Jensen, P.K., Lundsteen, C., et al. 2006. Systematic re-examination of carriers of balanced reciprocal translocations: A strategy to search for candidate regions for common and complex diseases. Eur. J. Hum. Genet. 14: 410-417.

Backx, L., Van Esch, H., Melotte, C., Kosyakova, N., Starke, H., Frijns, J.P., Liehr, T., and Vermeesch, J.R. 2007. Array painting using microdissected chromosomes to map chromosomal breakpoints. Cytogenet. Genome Res. 116: 158-166.

Barrett, T., Troup, D.B., Wilhite, S.E., Ledoux, P., Rudnev, D., Evangelista, C., Kim, I.F., Soboleva, A., Tomashevsky, M., and Edgar, R. 2007. NCBI GEO: Mining tens of millions of expression profiles-Database and tools update. Nucleic Acids Res. 35: D760-D765.

Blackwood, D.H., Fordyce, A., Walker, M.T., St. Clair, D.M., Porteous, D.J., and Muir, W.J. 2001. Schizophrenia and affective disorders-Cosegregation with a translocation at chromosome $1 \mathrm{q} 42$ that directly disrupts brain-expressed genes: Clinical and P300 findings in a family. Am. J. Hum. Genet. 69: 428-433.

Bugge, M., Bruun-Petersen, G., Brondum-Nielsen, K., Friedrich, U., Hansen, J., Jensen, G., Jensen, P.K., Kristoffersson, U., Lundsteen, C., Niebuhr, E., et al. 2000. Disease associated balanced chromosome rearrangements: A resource for large scale genotype-phenotype delineation in man. J. Med. Genet. 37: 858-865.

Drescher, U., Bonhoeffer, F., and Muller, B.K. 1997. The Eph family in retinal axon guidance. Curr. Opin. Neurobiol. 7: 75-80.

Erdogan, F., Chen, W., Kirchhoff, M., Kalscheuer, V.M., Hultschig, C., Muller, I., Schulz, R., Menzel, C., Bryndorf, T., Ropers, H.H., et al. 2006. Impact of low copy repeats on the generation of balanced and unbalanced chromosomal aberrations in mental retardation. Cytogenet. Genome Res. 115: 247-253.

Feldheim, D.A., Nakamoto, M., Osterfield, M., Gale, N.W., DeChiara, T.M., Rohatgi, R., Yancopoulos, G.D., and Flanagan, J.G. 2004. Loss-of-function analysis of EphA receptors in retinotectal mapping. J. Neurosci. 24: 2542-2550.

Fiegler, H., Gribble, S.M., Burford, D.C., Carr, P., Prigmore, E., Porter, K.M., Clegg, S., Crolla, J.A., Dennis, N.R., Jacobs, P., et al. 2003. Array painting: A method for the rapid analysis of aberrant chromosomes using DNA microarrays. J. Med. Genet. 40: 664-670.

Garshasbi, M., Hadavi, V., Habibi, H., Kahrizi, K., Kariminejad, R., Behjati, F., Tzschach, A., Najmabadi, H., Ropers, H.H., and Kuss, A. 2008. A defect in the TUSC3 gene is associated with autosomal recessive mental retardation. Am. J. Hum. Genet. (in press).

Gleeson, P.A. and Schachter, H. 1983. Control of glycoprotein synthesis. J. Biol. Chem. 258: 6162-6173.

Gloyn, A.L., Ellard, S., Shepherd, M., Howell, R.T., Parry, E.M., Jefferson, A., Levy, E.R., and Hattersley, A.T. 2002. Maturity-onset diabetes of the young caused by a balanced translocation where the $20 \mathrm{q} 12$ break point results in disruption upstream of the coding region of hepatocyte nuclear factor-4alpha (HNF4A) gene. Diabetes 51: 2329-2333.

Gribble, S.M., Kalaitzopoulos, D., Burford, D.C., Prigmore, E., Selzer, R.R., Ng, B.L., Matthews, N.S., Porter, K.M., Curley, R., Lindsay, S.J., et al. 2007. Ultra-high resolution array painting facilitates breakpoint sequencing. J. Med. Genet. 44: 51-58.

Kirov, G., Gumus, D., Chen, W., Norton, N., Georgieva, L., Sari, M., O'Donovan, M.C., Erdogan, F., Owen, M.J., Ropers, H.H., et al. 2008.

\section{Genome Research}

www.genome.org 
Comparative genome hybridization suggests a role for NRXN1 and APBA2 in schizophrenia. Hum. Mol. Genet. 17: 458-465.

Korbel, J.O., Urban, A.E., Affourtit, J.P., Godwin, B., Grubert, F., Simons, J.F., Kim, P.M., Palejev, D., Carriero, N.J., Du, L., et al. 2007. Paired-end mapping reveals extensive structural variation in the human genome. Science 318: 420-426.

Lu, W., Quintero-Rivera, F., Fan, Y., Alkuraya, F.S., Donovan, D.J., Xi Q., Turbe-Doan, A., Li, Q.G., Campbell, C.G., Shanske, A.L., et al. 2007. NFIA haploinsufficiency is associated with a CNS malformation syndrome and urinary tract defects. PLoS Genet 3: e80. doi: 10.1371/journal.pgen.0030080.

Molinari, F.F., Morelle, W., Romano, S., de Lonlay, P., Tarpey, P.S., Teague, J., Edkins, S., Futreal, P.A., Stratton, M.R., Partington, M., et al. 2007. Oligosaccharyltransferase subunits mutations in non-syndromic mental retardation. In 13th International Workshop on Fragile $X$ and $X$-Linked Mental Retardation. Venice, Italy.

Schachter, H., Brockhausen, I., and Hull, E. 1989. High-performance liquid chromatography assays for $\mathrm{N}$-acetylglucosaminyltransferases involved in N- and O-glycan synthesis. Methods Enzymol. 179: 351-397.

Taipale, M., Kaminen, N., Nopola-Hemmi, J., Haltia, T., Myllyluoma, B., Lyytinen, H., Muller, K., Kaaranen, M., Lindsberg, P.J., Hannula-Jouppi, K., et al. 2003. A candidate gene for developmental dyslexia encodes a nuclear tetratricopeptide repeat domain protein dynamically regulated in brain. Proc. Natl. Acad. Sci. 100: $11553-11558$.

Tommerup, N. 1993. Mendelian cytogenetics. Chromosome rearrangements associated with mendelian disorders. J. Med. Genet. 30: $713-727$.

Tzschach, A., Hoffmann, K., Hoeltzenbein, M., Bache, I., Tommerup, N., Bommer, C., Korner, H., Kalscheuer, V., and Ropers, H.H. 2006.

Molecular characterization of a balanced chromosome translocation in psoriasis vulgaris. Clin. Genet. 69: 189-193.

Ullmann, R., Turner, G., Kirchhoff, M., Chen, W., Tonge, B., Rosenberg, C. Field, M., Vianna-Morgante, A.M., Christie, L., Krepischi-Santos, A.C., et al. 2007. Array CGH identifies reciprocal 16p13.1 duplications and deletions that predispose to autism and/or mental retardation. Hum. Mutat. 28: 674-682.

Veltman, I.M., Veltman, J.A., Arkesteijn, G., Janssen, I.M., Vissers, L.E., de Jong, P.J., van Kessel, A.G., and Schoenmakers, E.F. 2003. Chromosomal breakpoint mapping by arrayCGH using flow-sorted chromosomes. Biotechniques 35: 1066-1070.

Warburton, D. 1991. De novo balanced chromosome rearrangements and extra marker chromosomes identified at prenatal diagnosis: Clinical significance and distribution of breakpoints. Am. J. Hum. Genet. 49: 995-1013.

Williamson, R.E., Darrow, K.N., Michaud, S., Jacobs, J.S., Jones, M.C. Eberl, D.F., Maas, R.L., Liberman, M.C., and Morton, C.C. 2007. Methylthioadenosine phosphorylase (MTAP) in hearing: Gene disruption by chromosomal rearrangement in a hearing impaired individual and model organism analysis. Am. J. Med. Genet. A 143: $1630-1639$.

Wirth, J., Nothwang, H.G., van der Maarel, S., Menzel, C., Borck, G. Lopez-Pajares, I., Brondum-Nielsen, K., Tommerup, N., Bugge, M., Ropers, H.H., et al. 1999. Systematic characterisation of disease associated balanced chromosome rearrangements by FISH: Cytogenetically and genetically anchored YACs identify microdeletions and candidate regions for mental retardation genes. J. Med. Genet. 36: 271-278.

Received January 14, 2008; accepted in revised form March 4, 2008. 


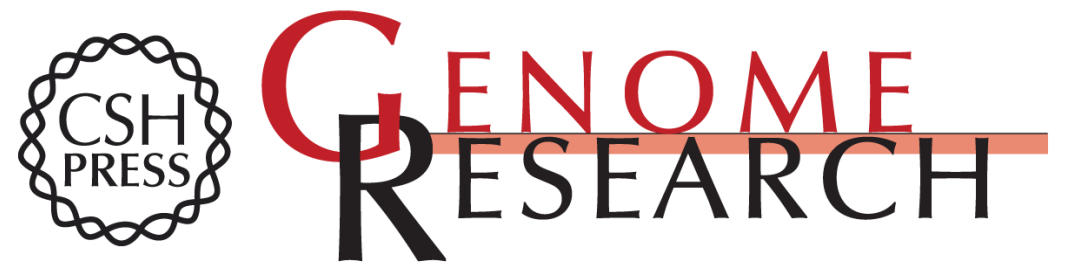

\section{Mapping translocation breakpoints by next-generation sequencing}

Wei Chen, Vera Kalscheuer, Andreas Tzschach, et al.

Genome Res. 2008 18: 1143-1149 originally published online March 7, 2008

Access the most recent version at doi:10.1101/gr.076166.108

Supplemental http://genome.cshlp.org/content/suppl/2008/05/22/gr.076166.108.DC1
Material

References This article cites 27 articles, 12 of which can be accessed free at:

http://genome.cshlp.org/content/18/7/1143.full.html\#ref-list-1

\section{License}

Email Alerting Receive free email alerts when new articles cite this article - sign up in the box at the Service top right corner of the article or click here.

\section{Affordable, Accurate Sequencing.}

